\title{
The nature of isoenzymes
}

\author{
A. L. LATNER \\ From the University Department of Clinical Biochemistry, Royal Victoria Infirmary, Newcastle upon Tyne
}

Many enzymes are known to exist in multiple molecular forms; in fact, it is now believed to be the exception rather than the rule for an enzyme to exist in only one form (Kaplan, 1968). The term 'isoenzyme' has been applied to each of these forms and, for the time being, it has been decided to retain a broad definition of isoenzyme such as 'one of a series of different proteins with similar enzymatic activity'. It is likely that eventually it will be established that the multiple forms of enzymes are merely a special example of the structural variations that occur in proteins generally, of which haemoglobin is a well known example, but until more is known of the molecular structure of isoenzymes, it would be unwise to adopt too narrow a definition. Some authorities have limited the term to the multiple forms of an enzyme which are all present in one tissue or organ of an individual plant or animal or in a culture of a unicellular organism. This narrow definition would not embrace the multiple forms of alkaline phosphatase (EC 3.1.3.1) which are found in many different tissues, but which are nevertheless customarily referred to as isoenzymes. The broad definition above also includes such examples as cytoplasmic and mitochondrial malate dehydrogenase (EC 1.1.1.37) although these have been regarded as entirely separate enzymes, each with its own isoenzymes; however, hybrids of these two enzymes have been prepared in vitro (Chilson, Kitto, Pudles, and Kaplan, 1966). The mitochondrial and cytoplasmic forms of aspartate aminotransferase are also very different in their properties. As has already been indicated, however, such difficulties will undoubtedly be resolved when the molecular composition and structure of the various 'isoenzymes' has become known.

It is now common knowledge that proteins are composed of one or more polypeptide chains and that their molecular structure can be subdivided, into primary, secondary, tertiary, and quaternary components. The primary is of course the aminoacid sequence, which is also the final arbiter of the eventual shape of the molecule. The secondary structure is the occurrence within the polypeptide chains of alpha helices, the rigid parts of the chain, and the looser bent sequences-largely, but by no means entirely-determined by the presence of prolines The tertiary component, or final shape of a poly $\overrightarrow{0}$ peptide, is brought about by the three-dimensionat bending of the secondary form by forces such ag hydrogen bonding, internal interactions of hydrophobic groupings, electrostatic bonding, van de Waals interactions, disulphide bridges, and the like? In accordance with thermodynamic considerations? there is little doubt that the final form is that struc $\overrightarrow{\Phi_{0}}$ ture with minimal energy content. Most proteins contain more than one polypeptide and the com bination of these makes up the quaternary component of structure.

It is now accepted that each polypeptide is syn thesized as a result of a message initiated in a cistron, often loosely referred to as a gene, and thus in one sense the old adage 'one gene, one enzyme to incorrect, since the quaternary structure of gain enzyme is frequently made up of different p ify peptides, which individually have no enzymâtie activity. Hence genetic considerations are capable of explaining the existence of a number of differerfif types of isoenzymes.

\section{Methods of Demonstration}

Isoenzymes may be demonstrated by the position they have taken up after electrophoresis, isoelectrit focusing, or column chromatography, as well as. by differences in physical properties, chemicas constitution, kinetics, or reactions with antiser (Uriel, 1963). The most popular of these methods has been electrophoresis in some form of gel (agas starch, or acrylamide). By the use of specific staining for enzyme activity it is then possible to demonstrate the positions taken up by the individual isoenzymes? For example, the five bands obtained with humag lactate dehydrogenase (EC 1.1.1.27) after starẹ gel electrophoresis are shown in Figure 1. The other techniques of detection are particularly useful wheg such band separation cannot be achieved by electrophoresis.

As shown in the Table, it is now realized that there are a number of different isoenzyme types. Some a genetically determined and others are not. 


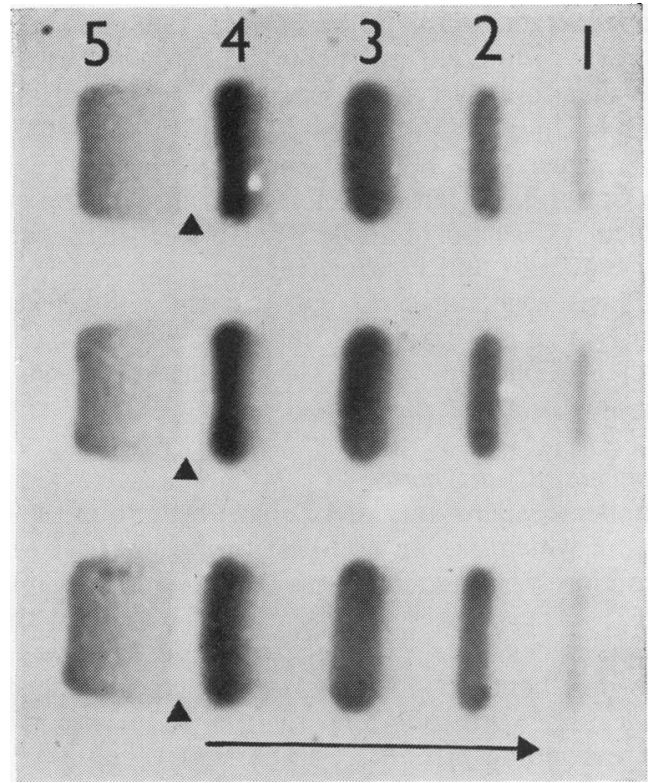

Fig. 1 Typical five-band patterns of lactate dehydrogenase after starch gel electrophoresis. The arrow points in the direction of the anode.

\begin{tabular}{ll}
\hline Genetically Determined & Other Types \\
\hline Multiple forms due to separate genes & Polymerization \\
Duplicate enzymes & Conformers \\
Variants & Artefacts \\
\hline
\end{tabular}

Table Isoenzyme types

\section{GENETICALLY DETERMINED ISOENZYMES}

There are three main categories of genetically determined isoenzymes. (1) Those formed by varying combinations of the constituent polypeptides of greatly differing amino acid composition, which are themselves governed by separate genes at different loci. These are found in all members of a species. (2) Those termed 'duplicate isoenzymes' which occur as a result of small variations in the structure of one or more of the polypeptides. These also are present in all members of an affected strain or species, and are thought to be determined by related genes at different loci, which have arisen from chromosomal duplication and mutation. (3) Those due to mutant alleles at a single locus, each allele determining a structurally distinct version of the particular polypeptide; these variants are found only in some individuals of a species.

\section{Due to separate genes}

Lactate dehydrogenase (LD) is a typical example of this type of isoenzyme system. The enzyme in human beings and in a a variety of other animals exists in five isoenzyme forms. This is because the enzyme molecule is a tetramer, made up of two different polypeptides ( $M$ and $\mathbf{H}$ ). If these are arranged in groups of four it is possible to obtain only five different combinations as shown in Figure 2. There is now ample evidence, largely from the study of isoenzyme variants, that each polypeptide is produced by a different gene and that they differ greatly in their amino acid composition, their immunological and physical properties, and in their contribution to the catalytic activity of the enzyme molecule. This information has come about from a study of those isoenzymes which move fastest $\left(L_{1}\right)$ and slowest $\left(L_{5}\right)$ during electrophoresis at $p \mathrm{H} \mathrm{8.6.} \mathrm{These} \mathrm{have} \mathrm{molecules} \mathrm{made} \mathrm{up} \mathrm{respectively}$ of four $\mathrm{H}$ polypeptides $\left(\mathrm{H}_{4}\right)$ and four $\mathrm{M}$ polypeptides $\left(\mathbf{M}_{4}\right)$. If these individual isoenzymes are frozen in $0 \cdot 1 \mathrm{M}$ sodium phosphate buffer of $p \mathrm{H}$ 7.0 in $1.0 \mathrm{M} \mathrm{NaCl}$, they dissociate into their subunits. On subsequent thawing, the dissociated subunits recombine to reform the original isoenzyme. If, however, mixtures of the $\mathrm{H}_{4}$ and $\mathrm{M}_{4}$ isoenzymes are frozen and thawed in this fashion, the subunits recombine at random and form all five of the LD isoenzymes (Markert, 1963) as shown in Figure 3. Thus the existence of five isoenzymes can be fully explained in terms of the action of two genes producing two different polypeptide subunits. A sixth isoenzyme of LD has been found in testis and seminal fluid (Blanco and Zinkham, 1963), and this is now known to depend on a different gene. The latter would appear to be switched on when the

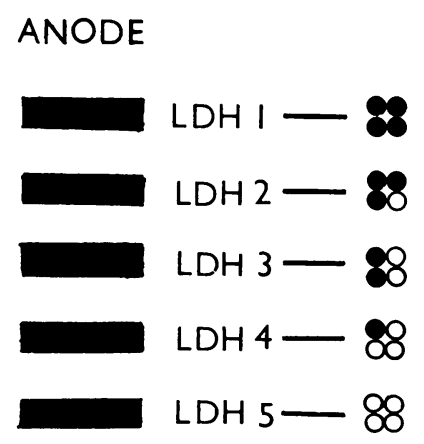

\section{CATHODE}

Fig. 2 Diagrammatic representation of the lactate dehydrogenase five-band pattern and the molecular structure of each isoenzyme tetramer. $H$ subunits are represented by closed circles and $M$ subunits by open circles. 


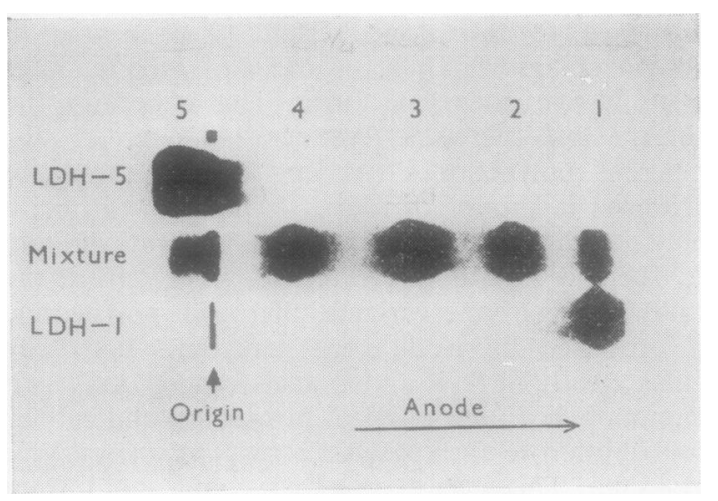

Fig. 3 Effect of dissociation and recombination of pure $L D H-1$ and pure $L D H-5$ and of a mixture of the two (after Markert, 1963).

other two genes in testicular cells are switched off. It is a matter of some interest that yet another gene controls the synthesis of an additional isoenzyme in the eyes and brain tissues of nearly all fish (Markert, 1968).

Although there are a number of exceptions, the $\mathrm{H}_{4}$ type of isoenzyme tends to predominate in those tissues which respire aerobically, whereas the $\mathbf{M}_{4}$ tends to predominate in those tissues which respire more or less anaerobically. $\mathrm{The}^{\mathrm{H}_{4}}$ isoenzyme shows much more substrate inhibition by pyruvate (Latner, Siddiqui, and Skillen, 1966) and product inhibition by lactate (Stambaugh and Post, 1966) than does the $\mathrm{M}_{4}$. It has been suggested that the $\mathrm{H}_{4}$ molecule allows pyruvate to accumulate and so favours oxidation along the pathway of the tricarboxylic acid cycle, whereas the $\mathbf{M}_{4}$ would allow the glycolytic pathway to be completed as far as lactate. This is strongly denied by Vesell (1965) but on the whole the evidence in many species is in favour of this interpretation (Kaplan, 1968). It is perhaps of interest that, according to Agostoni, Vergani, and Villa (1966), $\mathrm{H}_{4}$ tends to be attached to the membranes of mitochondria, where the oxidative processes of cells are mainly located.

The other three isoenzymes which are composed of the two different polypeptide subunits, are known as hybrids.

There are a number of other isoenzyme systems which have multiple forms due to separate genes and are capable of forming hybrids. Amongst these should be mentioned ketose 1-phosphate aldolase $^{1}$ (EC 4.1.2.7) a tetramer (Penhoet, Rajkumar, and Rutter, 1966), and creatine kinase (EC 2.7.3.2.), which exists as a dimer (Dawson, ${ }^{1}$ Also known as aldolase, or fructose 1-phosphate aldolase.
Eppenberger, and Eppenberger, 1968) made up from two different polypeptides. In the latter theres are therefore two main pure types characteristic of $\frac{5}{0}$ muscle and brain respectively, and a third hybrid. type which can also be found in vivo. Glycogen $\overrightarrow{\vec{s}}$ phosphorylase (EC 2.4.1.1.) is another enzyme? which exists in multiple forms due to separate genes (Krebs and Fischer, 1962).

It has been suggested, particularly with reference to LD, that isoenzymes of this type arose by chromosomal duplication with subsequent mutations ats the new or at the parent loci.

\section{Duplicate isoenzymes}

Duplicate isoenzymes of LD have been found in the mouse which has, in addition to the usual $\mathrm{H}$ gene, is two closely related $M$ genes (Costello and Kaplan, 1963). The hybrid combinations of these three ${ }_{-}^{+}$ polypeptides give rise not to the usual five iso-io enzymes, but to 15 (Fig. 4) which include fiveo molecules corresponding to the $\mathbf{M}_{4}$ types, fourcorresponding to $\mathrm{M}_{3}$, three corresponding to $\mathrm{M}_{2} \mathrm{H}_{2}$, two corresponding to $\mathrm{M}_{1} \mathrm{H}_{3}$, and of course? only one to $\mathrm{H}_{4}$. When separated by electrophoresisê these appear as sub-bands around the positions of the five principal isoenzymes. Mouse ketose 1-e phosphate aldolase also has duplicate forms (Mastes, 1967).

Haddock LD has two $M$ types (Kaplan, 19 which will hybridise only with each other to giwe five electrophoretic bands in the $\mathbf{M}_{4}$ area; the onlyo other isoenzyme of haddock LD is therefore the $\mathrm{H}_{4} \frac{\mathbb{2}}{2}$ entity, giving a total of six electrophoretic bands.

Variants due to alleles of the same gene

Atypical isoenzyme patterns occurring in only ac few individuals are attributed to mutant alleles. Examples of such mutations have been found ino several species including man. Although the reported ${ }_{3}$ differences in amino acid sequence of the enzymesare small, there may be large differences in theiro physical and catalytic properties. In the case of bovine carboxypeptidase (EC 3.4.2.1.) isoenzymes? differ by only a single amino acid (Walsh, Ericcson and Neurath, 1966).

Alleles have been found for both the $\mathbf{M}$ and $\mathbf{H} \bar{\sim}$ polypeptides of human LD. As such mutations are not necessarily identical, various isoenzyme patterns $\mathcal{O}^{-}$ occur, as illustrated in Fig. 5 which depicts dia grammatically the LD variants in man reported byo different authors (Latner and Skillen, 1968). Ino Rana pipiens such polymorphism has been founct only with the $\mathrm{H}$ type (Kaplan, 1968).

Reference must also be made to the geneticallyo determined variant of human serum cholinesterase? (EC 3.1.1.8) which renders certain individuals 


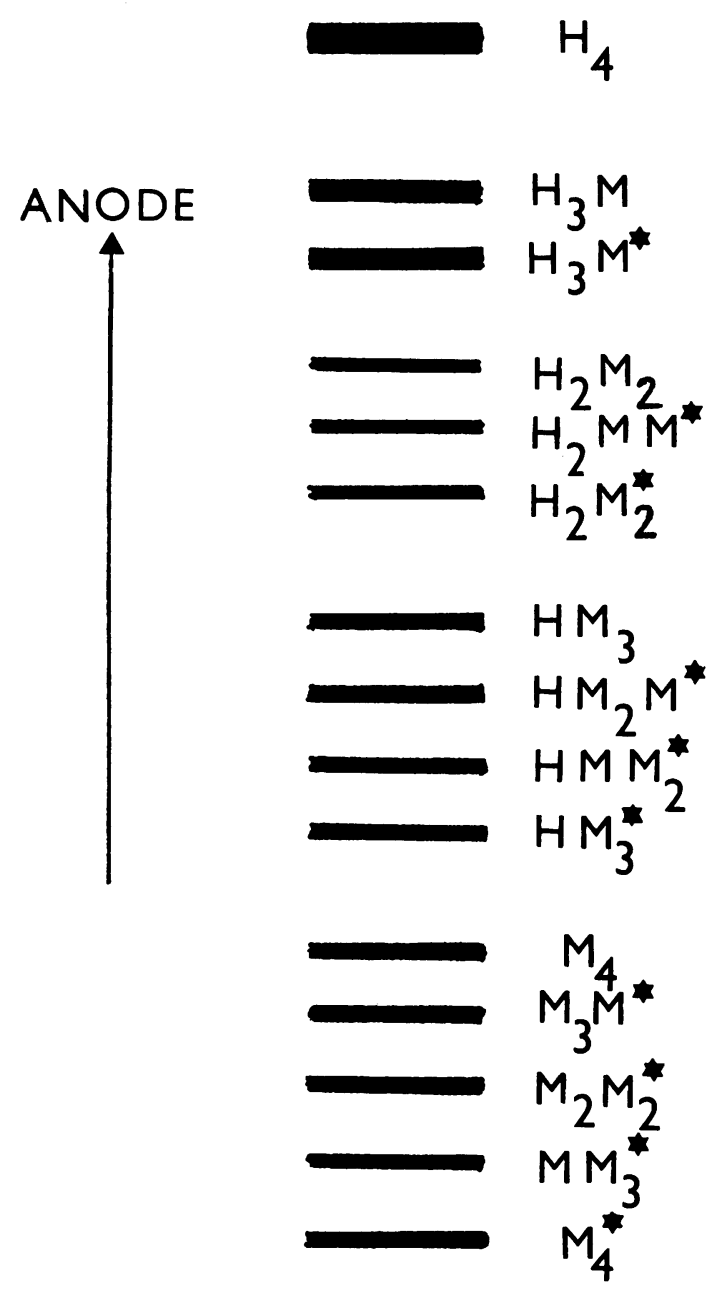

Fig. 4 Diagrammatic representation of duplicate isoenzymes and their subunit structure in certain strains of mouse. This results from two different genes for the $M$ subunit. The new gene is denoted by an asterisk.

more sensitive to the action of succinylcholine (Kalow and Genest, 1957) and to the variants of human placental alkaline phosphatase (Robson and Harris, 1965) and human red cell acid phosphatase (EC 3.1.3.2) (Hopkinson, Spencer, and Harris, 1963).

A more complex situation arises with Esch. coli alkaline phosphatase, which is a dimer of two identical polypeptides (Rothman and Byrne, 1963). In some (wild) strains isoenzymes have appeared due to changes in the amino-acid sequence. However, it appears that this change occurs in the cyto-

\begin{tabular}{|c|c|c|c|c|c|}
\hline 1 & 1 & 1 & 1 & 1 & (A) \\
\hline & & 11 & 11 & 1 & (B) \\
\hline$\square$ & $\square$ & 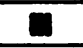 & II & 1 & (C) \\
\hline$m$ & $\mathrm{man}$ & 111 & II & 1 & (D) \\
\hline$\square$ & $\overline{0}$ & $m$ & $\pi$ & 1 & (E) \\
\hline 1 & $\pi$ & m & 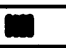 & $\square$ & (F) \\
\hline 1 & 1 & 11 & 1 & 1 & (G) \\
\hline $\mathrm{LDH}-5$ & $\mathrm{DH}-4$ & $\mathrm{DH}-3$ & $\mathrm{DH}-\mathrm{C}$ & $\mathrm{DH}-1$ & \\
\hline
\end{tabular}

Fig. 5 Diagrammatic representation of reported variants of human lactate dehydrogenase arising from genetic mutations (after Latner and Skillen, 1968).

plasm after dimerization has occurred, and that it is therefore not necessarily genetically determined (Schlesinger and Anderson, 1968).

\section{ISOENZYMES NOT GENETICALLY}

DETERMINED

\section{Polymerization}

It is possible for multiple molecular forms to arise from the existence of different aggregates of the molecules of a specific enzyme. Such aggregation could lead to a variation in surface charge and so to a difference in behaviour during electrophoresis. It would appear that this is the basis of certain of the multiple molecular forms of human serum cholinesterase (LaMotta, McComb, and Wetstone, $1965)$ as well as some of the forms of $\beta$-galactosidase (EC 3.2.1.23) (Kaplan, 1968).

\section{Conformers}

It has already been indicated that the final threedimensional shape of a protein molecule is determined by minimal energy content. It is, however, consistent with thermodynamic considerations that there may be more than one stable form. This may arise because two different forms have very similar energy content or, probably more commonly, because it takes a relatively long time for one form to change into another. This could give rise to the existence of two molecular shapes as shown in Figure 6. These resemble each other closely except for the position in space of one small section of the molecule. Provided that the slight alteration in shape does not affect the active enzyme site, it would not interfere with an enzyme's action. The alteration in shape might nevertheless affect the overall surface charge and so produce a different behaviour during electrophoresis. This appears to be the case with mitochondrial malate dehydrogenase (MD). A good deal of work has been done with the chicken enzyme of which there are five 

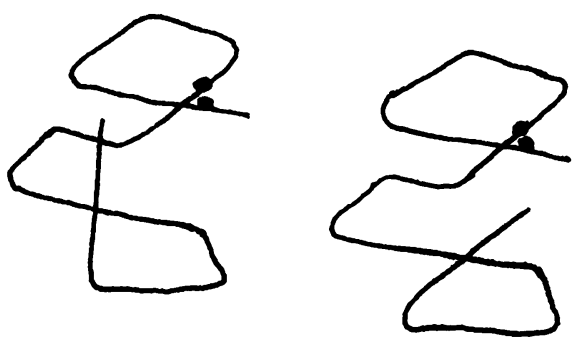

Fig. 6 Diagrammatic representation of two conformer enzyme molecules. Note that the polypeptide chain is bent slightly differently at the bottom, but the rest of each of the molecules is identical and the active sites (dark spots) are unaffected.

conformers designated A, B, C, D, and E. They have almost identical catalytic properties but different optical rotary and physical properties such as electrophoretic mobility. That these differences are due to variation in molecular conformation is supported by reversible denaturation experiments (Kitto, Wassarman, and Kaplan, 1966). Thus, it is possible to unwind a protein structure completely by subjecting it to an acid $p \mathrm{H}$. On restoring the $p \mathrm{H}$ to neutral, the original structure may occasionally be restored. When the procedure is applied to a separated conformer isoenzyme of chicken $\mathrm{MD}$, it first unwinds and then takes up the shapes of other conformers. However, some confusion has arisen because similar experiments with guanidine hydrochloride, which is another agent for opening up the structure of proteins, have given equivocal results.

Another conformational isoenzyme system is the brain form of creatine kinase of Galliform birds (Eppenberger, Eppenberger, and Kaplan, 1967). Cytoplasmic and mitochondrial aspartate aminotransferases also have been found to possess similar subforms which are possible conformers.

Despite the fact that they have different shapes, conformers closely resemble each other in respect of enzyme properties, and it seems highly likely that their existence has no functional significance.

\section{ARTEFACTS}

A variety of artefacts can give a false impression of the existence of isoenzymes. These may result from preparative procedures which give rise to changes such as deamidation or decarboxylation. Impurities in reagents used during preparation and electrophoresis can produce complexes with enzyme proteins which behave differently from the pure enzyme. It is also possible for serum enzymes to combine with other serum proteins and so allow electrophoresis to give rise to a variety of different bands (Latner? 1966). During isoelectric focusing, enzymes can combine with ampholyte and produce pseudo $\overrightarrow{7}$ heterogeneity. If an enzyme is contaminated by aproteolytic enzyme there may be a variable break $\vec{F}$ down of the non-active site portion, leaving enzymes activity intact; this would undoubtedly result in f $^{\circ}$ number of different bands being found after electro $\overline{\bar{E}}$. phoresis. It is possible that a number of digestive tract enzymes found to occur in multiple forms mas
result from this phenomenon.

Artefactual isoenzymes may also arise from the $\overrightarrow{0}$ fact that enzyme substrate specificity is by no means always strict, so that two different enzymes mase react with the same substrate. Alternatively, ar impurity in the substrate may result in one enzyme masquerading as another. Thus small amounts of alcohol dehydrogenase in tissue extracts can lead to confusion during studies of other dehydrogenas $\vec{E}$ enzymes since small amounts of ethanol may be present in the reagents, eg, in NAD preparations.

\section{Physiological Considerations}

A number of observations have been made which indicate that the existence of isoenzymes is of significance in relation to metabolic pathways. A $\odot$ mentioned previously, the in-vitro substrate product inhibition of the $\mathrm{H}_{4}$ and $\mathrm{M}_{4}$ types of lacto dehydrogenase has given the impression that thes two isoenzymes are important in the determination of oxidative or non-oxidative pathways of glucos breakdown respectively. This possibility seems to be supported by the distribution of lactate dehy drogenase isoenzymes in different muscles of variousbirds (Wilson, Cahn, and Kaplan, 1963), the rabbito the chicken, and human being (Dawson, Goodfriend: and Kaplan, 1964; Kaplan, 1964). Although Vese 8 does not agree with the evidence based on in-vitr substrate or product inhibition, he has recentl stated that the pathways may be determined by feedback allosteric effect, possibly by ketoglu? tarate, on the $M_{4}$ isoenzyme (Vesell, 1970). His group have shown, however, that aerobically respiring tissues such as heart actively destroy the. $\mathbf{M}_{4}$ isoenzyme and so maintain a pattern which is predominantly $\mathrm{H}_{4}$ (Fritz, Vesell, White, and Pruite, 1969).

Studies with rabbits and chickens have indicated that a number of the enzymes of the glycolytio pathway appear to exist in at least two forms (Papadopoulos and Velick, 1967; Joshi, Hooper Kuwaki, Sakurada, Swanson, and Handler, 1967: Dawson et al, 1968; Rouslin, 1967), one of which is predominant in muscle and the other in live? Those in muscle seem to be geared to glucose break 
down whereas those in liver are apparently geared to gluconeogenesis.

It has often been found in bacteria and yeasts that when a particular reaction is common to more than one metabolic sequence, the organism elaborates more than one enzyme to catalyse it. This is advantageous in that the end-products of one sequence will inhibit only the enzyme which catalyses the reaction for that sequence thus allowing other pathways to continue (Stadtman, 1968). It would perhaps be surprising if the same situation did not occur in animals and man, and on teleological grounds it might be expected that the existence of isoenzymes with somewhat different catalytic properties would be of advantage to the organism; the different distribution of a number of isoenzyme systems in tissues would certainly point to this.

Further evidence for the physiological role of LD isoenzymes rests on reports that $\mathrm{H}_{4}\left(\mathrm{LD}_{1}\right)$ tends to associate with the mitochondrial membrane (Agostoni et al, 1966) and $\mathbf{M}_{4}\left(\mathrm{LD}_{5}\right)$ with the nucleus (Güttler and Clausen, 1967). However, the work published so far on intracellular location of isoenzymes is unconvincing.

\section{References}

Agostoni, A., Vergani, C., and Villa, L. (1966). Intracellular distribution of the different forms of lactic dehydrogenase. Nature (Lond.), 209, 1024-1025.

Blanco, A., and Zinkham, W. H. (1963). Lactate dehydrogenases in human testes. Science, 139, 601-602.

Chilson, O. P., Kitto, G. B., Pudles, J., and Kaplan, N. O. (1966). Reversible inactivation of dehydrogenases. J. biol. Chem., 241, 2431-2445.

Costello, L. A., and Kaplan, N. O. (1963). Evidence for two forms of M-type lactate dehydrogenase in the mouse. Biochim. biophys. Acta (Amst.), 73, 658-660.

Dawson, D. M., Eppenberger, H. M., and Eppenberger, M. E. (1968). Multiple molecular forms of creatine kinases. Ann. N.Y. Acad. Sci., 151, 616-626.

Dawson, D. M., Goodfriend, T. L., and Kaplan, N. O. (1964). Lactic dehydrogenases: functions of the two types. Science, 143, 929-933.

Eppenberger, M. E., Eppenberger, H. M., and Kaplan, N. O. (1967). Evolution of creatine kinase. Nature (Lond), 214, 239-241.

Fritz, P. J., Vesell, E. S., White, E. L., and Pruitt, K. M. (1969). The roles of synthesis and degradation in determining tissue concentrations of lactate dehydrogenase-5. Proc. nat. Acad. Sci. (Wash.), 62, 558-565.

Güttler, F., and Clausen, J. (1967). Cellular compartmentalization of lactate dehydrogenase isoenzymes. Enzym. Biol. Clin., 8, 456.

Hopkinson, D. A., Spencer, N., and Harris, H. (1963). Red cell acid phosphatase variants: a new human polymorphism. Nature (Lond.), 199, 969-971.

Joshi, J. G., Hooper, J., Kuwaki, T., Sakurada, T., Swanson, J. R. and Handler, P. (1967). Phosphoglucomutase, V. Multiple forms of phosphoglucomutase. Proc. nat. Acad. Sci. (Wash.), 57, 1482-1489.

Kalow, W., and Genest, K. (1957). A method for the detection of atypical forms of human serum cholinesterase. Determination of dibucaine numbers. Canad.J. biochem. Physiol., 35, 339-346.

Kaplan, N. O. (1968). Nature of multiple molecular forms of enzymes. Ann. N.Y. Acad. Sci., 151, 382-399.

Kaplan, N. O. (1964). Lactate dehydrogenase: structure and function Brookhaven Symp. Biol., 17, 131-153.

Kitto, G. B., Wassarman, P. M., and Kaplan, N. O. (1966). Enzymatically active conformers of mitochondrial malate dehydrogenase. Proc. nat. Acad. Sci. (Wash.), 56, 578-585.

Krebs, E. G., and Fischer, E. H. (1962). Molecular properties and transformations of glycogen phosphorylase in animal tissues. Advanc. Enzymol., 24, 263-290.

LaMotta, R. V., McComb, R. B., and Wetstone, H. J. (1965). Isozymes of serum cholinesterase: a new polymerization sequence. Canad. J. Physiol. Pharmacol., 43, 313-318.

Latner, A. L. (1966). The binding of circulating enzymes by plasma proteins. In Transport Function of Plasma Proteins, edited by P. Desgrez, and P. M. De Traverse, pp. 121-127. Elsevier, Amsterdam

Latner, A. L., Siddiqui, S. A., and Skillen, A. W. (1966). Pyruvate inhibition of lactate dehydrogenase activity in human tissue extracts. Science, 154, 527-529.

Latner, A. L., and Skillen, A. W. (1968). Isoenzymes in Biology and Medicine. Academic Press, London.

Markert, C. L. (1963). Lactate dehydrogenase isozymes: dissociation and recombination of subunits. Science, 140, 1329-1330.

Markert, C. L. (1968). The molecular basis for isozymes. Ann. N.Y. Acad. Sci., 151, 14-40.

Masters, C. J. (1967). Characteristics of aldolase variformity. Biochem. biophys. Res. Commun., 28, 978-984.

Papadopoulos, C. S., and Velick, S. F. (1967). An isozyme of glyceraldehyde-3-phosphate dehydrogenase in rabbit liver. Fed. Proc., 26, 557.

Penhoet, E., Rajkumar, T., and Rutter, W. J. (1966). Multiple forms of fructose diphosphate aldolase in mammalian tissues. Proc. nat. Acad. Sci. (Wash.), 56, 1275-1282.

Robson, E. B., and Harris, H. (1965). Genetics of the alkaline phosphat ase polymorphism of the human placenta. Nature (Lond.), 207, 1257-1259.

Rothman, F., and Byrne, R. (1963). Fingerprint analysis of alkaline phosphatase of Escherichia coli K12.J. molec. Biol., 6, 330-340.

Rouslin, W. (1967). Properties and tissue distribution of chicken NAD-linked $\alpha$-glycerophosphate dehydrogenase ( $\alpha$-GPDH) isozymes. Fed. Proc., 26, 557.

Schlesinger, M. J., and Andersen, L. (1968). Multiple molecular forms of the alkaline phosphatase of Escherichia coli. Ann. N.Y. Acad. Sci., 151, 159-170.

Stadtman, E. R. (1968). The role of multiple enzymes in the regulation of branched metabolic pathways. Ann. N.Y. Acad. Sci., 151, 516-530.

Stambaugh, R., and Post, D. (1966). Effects of tissue extracts and temperature on lactate dehydrogenase isozymes. Biochim. biophys. Acta (Amst.), 122, 541-543.

Uriel, J. (1963). Characterization of enzymes in specific immuneprecipitates. Ann. N.Y. Acad. Sci., 103, 956-979.

Vesell, E. S. (1965). Lactate dehydrogenase isozymes: substrate inhibition in various human tissues. Science, 150, 1590-1592.

Vesell, E. S. (1970). The biological significance of isozymes. Clin. Chem., 16, 864.

Walsh, K. A., Ericcson, L. H., and Neurath, H. (1966). Bovine carboxypeptidase A variants resulting from allelomorphism. Proc. nat. Acad. Sci. (Wash.), 56, 1339-1344.

Wilson, A. C., Cahn, R. D., and Kaplan, N. O. (1963). Functions of the two forms of lactic dehydrogenase in the breast muscle of birds. Nature (Lond.), 197, 331-334. 